\title{
Atrial Arrhythmia by ECG Finding
}

National Cancer Institute

\section{Source}

National Cancer Institute. Atrial Arrhythmia by ECG Finding. NCI Thesaurus. Code C80503.

An electrocardiographic finding of an atypical cardiac rhythm resulting from a pathologic process in the cardiac atria. 